\title{
A COMPARATIVE STUDY OF RECONSTRUCTION NAILING VERSUS DYNAMIC HIP SCREW DEVICE IN THE SURGICAL MANAGEMENT OF INTERTROCHANTERIC FRACTURES
}

\author{
Pereddy Somashekhara Reddy ${ }^{1}$, Nikhil Ponugoti2, Venkata S. Jampana ${ }^{3}$ \\ ${ }^{1}$ Associate Professor, Department of Orthopaedics, Apollo Institute of Medical Sciences and Research Centre, Hyderabad. \\ ${ }^{2}$ Registrar, Department of Orthopaedics, Apollo Institute of Medical Sciences and Research Centre, Hyderabad. \\ ${ }^{3}$ Senior Registrar, Department of Orthopaedics, Apollo Institute of Medical Sciences and Research Centre, Hyderabad.
}

\begin{tabular}{l}
\hline ABSTRACT \\
BACKGROUND \\
Intertrochanteric fractures are one of the most common injuries sustained in patients over sixty years of age. In the current century \\
due to increased life expectancy and increased expectancy of a better quality of life, orthopaedic surgeons have a great challenge to \\
face in treating proximal femoral fractures and with decreased rate of complications. The surgical management of these fractures \\
has gone through array of implants and surgeries.
\end{tabular}

\section{MATERIALS AND METHODS}

The study conducted was time bound, hospital based, prospective comparative study. It was non-randomised as patients were segregated into group A (Recon nail) and group B (Dynamic hip screw) based on their choice.

\section{RESULTS}

Results were assessed in terms of length of stay, blood loss, fracture union, functional outcome, duration of surgery and complications.

\section{CONCLUSION}

Duration of surgery was assessed at the time of surgery between Recon nail and DHS groups. Blood loss and length of hospital stay were assessed and noted postoperatively. Functional outcome and fracture union are assessed. Procedure time for DHS (average time-128.83 minutes) was more compared to Recon nail (average time in the study group was 75 minutes). DHS being an open procedure there was more blood loss than Recon nail. Patients treated with DHS needed longer duration of hospital stay than Recon nail. Non-union and other complications were more in DHS group. Functional outcomes at 3 months were better in Recon nail (mean modified Harris hip score for Recon nail 44.1 versus DHS 41.07) which was due to less blood loss, shorter duration of surgery, decreased hospital stay and early ambulation.

\section{KEYWORDS}

Intertrochanteric Fracture, Recon Nail, DHS.

HOW TO CITE THIS ARTICLE: Reddy PS, Ponugoti N, Jampana VS. A comparative study of reconstruction nailing versus dynamic hip screw device in the surgical management of intertrochanteric fractures. J. Evolution Med. Dent. Sci. 2016;5(99):7224-7230, DOI: 10.14260/jemds/2016/1635

\section{BACKGROUND}

Intertrochanteric fractures are one of the most common injuries sustained in patients over sixty years of age. These fractures are one of the most common fractures occurring in the elderly as emphasised by Smith Peterson, "Human beings come into this world through pelvis and leave this world through broken hips". Some of the factors found to be associated with a patient sustaining an intertrochanteric fracture rather than femoral neck fracture include advancing age, increased dependency in activities of daily living and a history of osteoporosis related (fragility) fractures.

Financial or Other, Competing Interest: None.

Submission 04-11-2016, Peer Review 28-11-2016,

Acceptance 04-12-2016, Published 10-12-2016.

Corresponding Author:

Dr. Pereddy Somashekhara Reddy,

Associate Professor,

Department of Orthopaedics,

Apollo Institute of Medical Sciences

and Research Centre,

Hyderabad.

E-mail: drpereddysr@gmail.com

DOI: $10.14260 /$ jemds/2016/1635

(c) $($ ) $($ )
Before the introduction of suitable fixation devices in the 1960s, treatment for intertrochanteric fractures was nonoperative, consisting of prolonged bed rest in traction until fracture healing occurred, which was associated with high complication rates; typical problems included decubitus ulcers, urinary tract infection, joint contractures, pneumonia, and thromboembolic complications, resulting in a high mortality rate. In the current century due to increased life expectancy and increased expectancy of a better quality of life, the orthopaedic surgeons have a great challenge to face in treating proximal femoral fractures and with decreased rate of complications. The surgical management of these fractures has gone through array of implants and surgeries.

The type of implant used has an important influence on complications of fixation. Sliding devices like the Dynamic hip screw (DHS), Sliding hip screw (SHS) have been extensively used for fixation. However, if the patient weight bears early, especially in comminuted fractures, these devices can penetrate the head or neck, bend, break or separate from the shaft.

Intramedullary devices like the DePuy Reconstruction nail (Recon nail), Gamma nail, Proximal femoral nail (PFN), Trochanteric fixation nail (TFN), Proximal femoral nail antirotation (PFNA) have been reported to have an advantage in 
such fractures as their placement allowed the implant to lie closer to the mechanical axis of the extremity, thereby decrease the lever arm and bending moment on the implant. They can also be inserted faster, with less operative blood loss and allow early weight bearing with less resultant shortening on long term followup.

The purpose of present study is to verify the theoretical advantages of the Recon nail over the dynamic hip screw device and also whether it actually alters the eventual functional outcome of the patient.

\section{MATERIALS AND METHODS}

The study conducted was time bound, hospital based, prospective comparative study. It was non-randomised as patients were segregated into group A (Recon nail) and group B (Dynamic hip screw) based on their choice. Study period: August 2013 to December 2014. Study location: Apollo Health City, Jubilee Hills, Hyderabad. During study period, we were able to enrol 60 patients operated by either by Recon nail or by DHS (30 subjects in each group.) who met the inclusion and exclusion criteria.

All patients above 18 years of age with fresh intertrochanteric fractures and who were able to walk prior to the fracture were included in the study.

Patients with pathological fractures, active infection, concurrent serious medical illnesses and non-traumatic disorders were excluded from the study.

\section{Study Procedure}

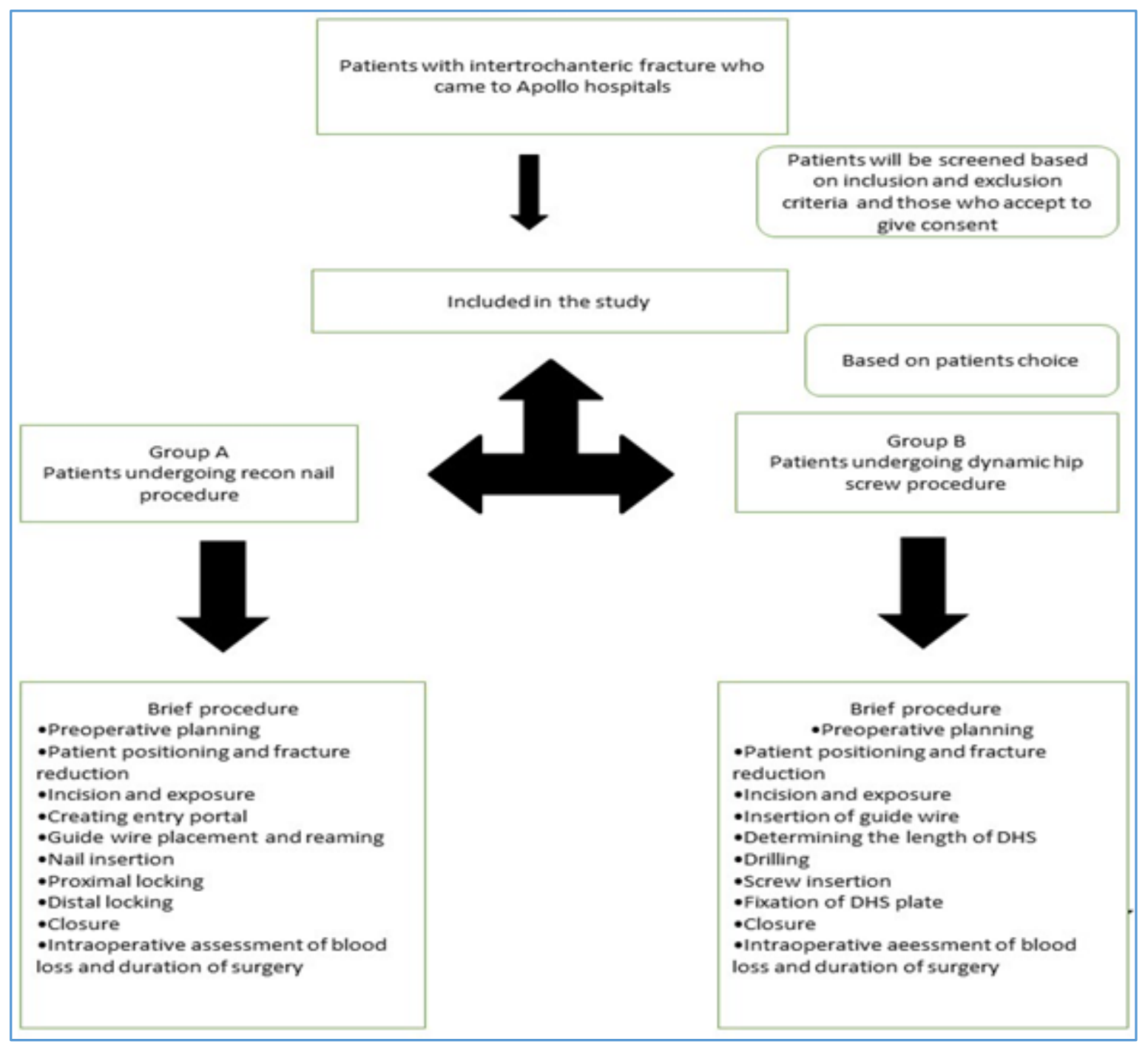

The mode of injury was classified under 2 different categories taking into consideration whether the injury was due to high energy like road traffic accident, fall from height or low energy like trivial fall. In our study, $76.67 \%$ of fractures were due to low energy injury like trivial fall.

No open fractures were encountered in this series. The patients were taken up for surgery on the next elective operation day. Adequate blood transfusion and other supportive measures were given depending on the preoperative condition of the patient and blood loss during surgery.

The fractures were fixed with either Recon nailing or dynamic hip screw fixation. Allocation of the fractures to each treatment group was done on basis of patient's choice. Of the 60 patients in the study, 30 were treated with Recon nailing and 30 with dynamic hip screw fixation. The duration of surgery was recorded intraoperatively. Postoperatively, blood loss was calculated using modified Gross formula, blood loss and length of stay was noted. All patients received injectable 
antibiotic (cephalosporins) given one hour before surgery and continued postoperatively 2 doses. In total, 3 intravenous doses of antibiotics are given. Oral cephalosporins were continued for next 3 to 4 days. Aminoglycosides were added intraoperatively if the procedure was prolonged. Analgesic was initially given in IV or IM route for 2 to 3 postoperative days and then orally for few days. We did use low molecular weight heparin and thromboxane stockings as a deep vein thrombosis prophylaxis in all our patients.

\section{Study Outcomes and Measurement}

Duration of surgery was assessed at the time of surgery between Recon nail and DHS groups.

Blood loss and length of hospital stay were assessed and noted postoperatively.

Functional outcome and fracture union are assessed at regular followup intervals of 3 months and 6-9 months respectively.

Independent $t$ test was used to compare characteristics of duration of surgery, blood loss, length of stay, functional outcome with Harris hip scores at 3 months and 9 months between the two groups.

Chi square test was used to assess fracture union and final outcome of patients between the two groups.

\section{Study Analysis Plan}

Descriptive statistics with demographic details of study patients was generated with respect to age, gender, duration from initial injury to surgery, side affected, mode of injury, surgery done, duration of surgery, blood loss and the length of hospital stay for the two procedures was compared.

Data at regular followup intervals postop 6 weeks, 3 months and 6-9 months were collected to assess the functional outcome and fracture union, they were compared using appropriate statistical tests.

Chi Square analysis was used to ascertain the statistical significance in the differences of the categorical variables and independent $t$ test was used for continuous variables. $P$ value is considered significant if it was $<0.05$.

\section{RESULTS}

\section{Demographic Data}

1. Age: In our study, the minimum age of the patient was 42 years and maximum was 84 years with a mean age of 63.05 and a standard deviation of 10.15 .

2. Gender distribution: Out of 60 patients, 35 were female and 25 were male patients which accounts to $58.33 \%$ and $41.67 \%$ respectively.

3. Side of Injury: Majority of the injuries (35) involved the left side (58.33\%).

4. Mode of Injury: Majority (76.67\%) of the patients sustained the injury due to a trivial fall on the hip.

5. Type of fracture: Majority (65\%) of the fractures belonged to the A2 category followed by A3 (21.67\%) and A1 (13.33\%) categories.

\section{Study Outcomes}

1. Length of hospital stay: Majority of the patients got discharged by the 4th day postoperatively. The minimum duration was 2 days and the maximum was 7 days with a mean stay period of 3.82 days and a standard deviation of 0.93 .
2. Fracture union: Excellent results were found with a vast majority of the patients (93.33\%) showing bony union at the fracture site.

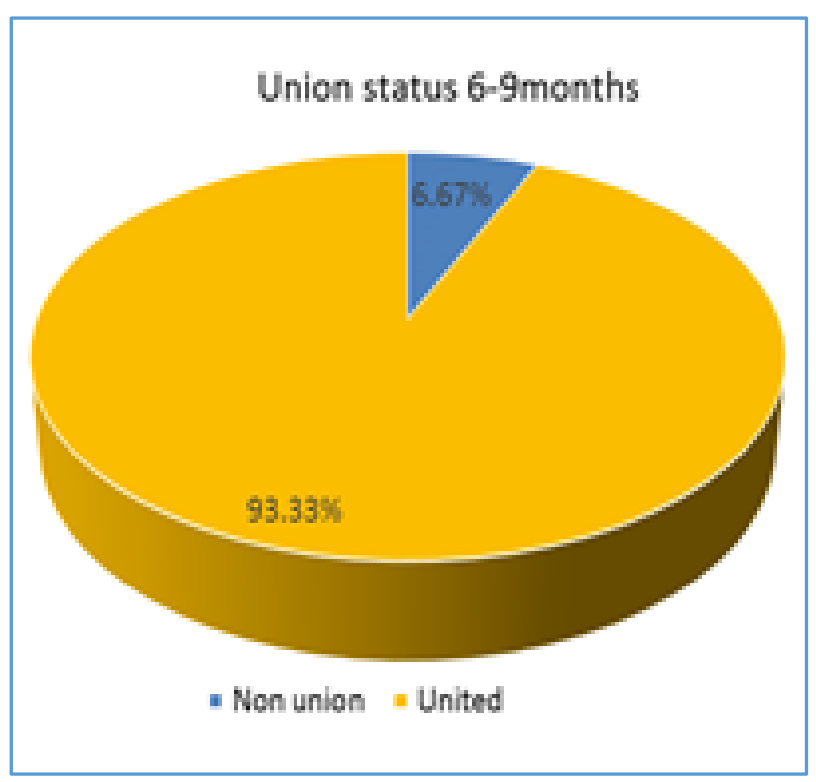

3. Functional Outcome: Majority of the patients belonged to the "good" and "excellent" categories.

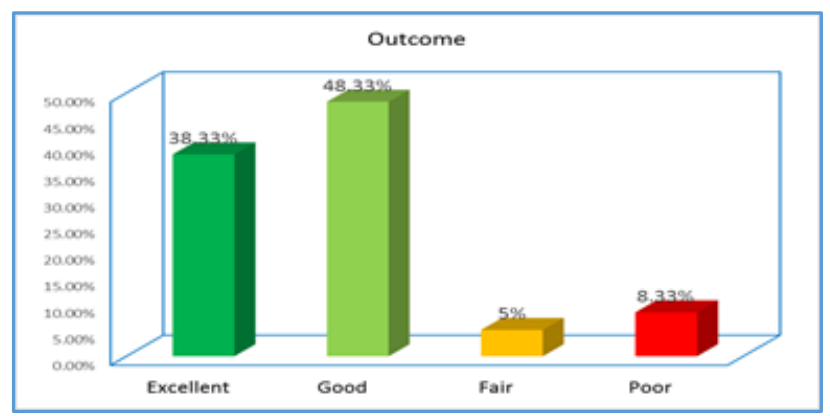

4. Duration of Surgery: The minimum duration of the surgery in our study was 45 minutes and the maximum was 160 minutes with a mean of 101.92 and standard deviation of 31.64 .

5. Blood loss: The minimum blood loss in our study cases was $102.4 \mathrm{~mL}$ whereas the maximum was $389.2 \mathrm{~mL}$ with an average (mean) blood loss of $205.27 \mathrm{~mL}$ and standard deviation of 70.57 .

6. Harris hip score at 9 months: The average Harris hip score at the end of 9 months in our study was 87.25 with a minimum of 66 and a maximum of 98 .

7. Complications: There was 1 case with screw back out and 1 case with total implant failure leading to non-union in Recon nail group, there were 2 cases with total implant failure leading to non-union and 1 case with non-union as complication in DHS group.

\section{Sub-Group Analysis}

1. Duration of Surgery versus Method of fixation: The average duration of surgery for Recon nail was $75(+/-$ 14.3) $\mathrm{min}$. and for DHS was $128.83(+/-18.227) \mathrm{min}$. Comparing the results with $t$ test gave a P value of $<0.001$. It suggests that the mean operating time for DHS is more than Recon nail. 


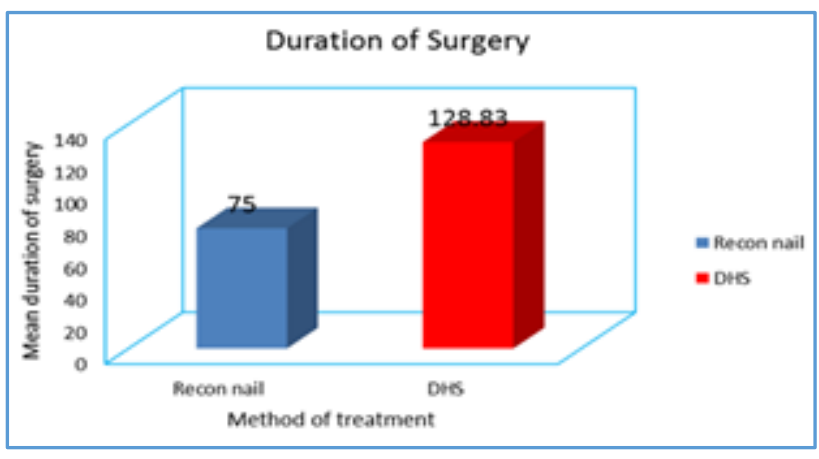

2. Blood loss versus Method of fixation: The average Blood loss during surgery for Recon nail was $150.61(+/-28.75)$ $\mathrm{ml}$ and for DHS was 259.94(+/-55.89) mL. Comparing the results with t test gave a $P$ value of $<0.001$. It suggests that there is more blood loss during surgery among DHS patients than Recon nail patients.

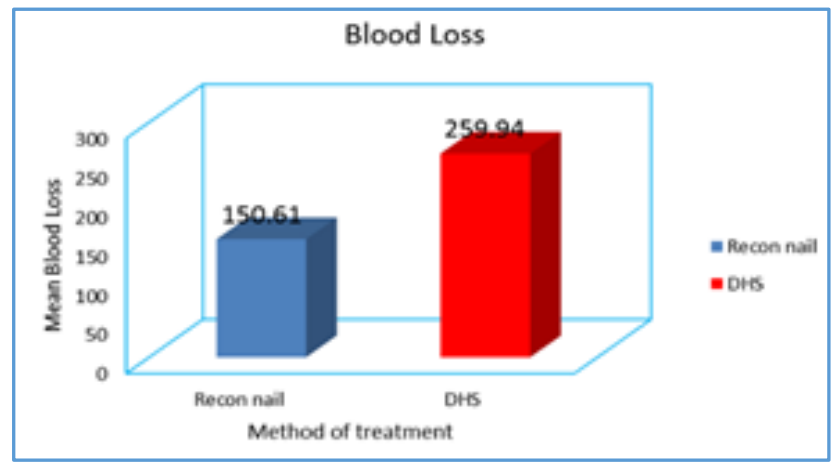

3. Length of stay versus Method of fixation: The average length of stay in hospital in days for Recon nail was 3.33 (+/-.758) days and for DHS was 4.3(+/-.837) days. Comparing the results with $t$ test gave a $\mathrm{P}$ value of $<0.001$, statistically significant suggesting DHS patients need prolonged stay in hospitals.

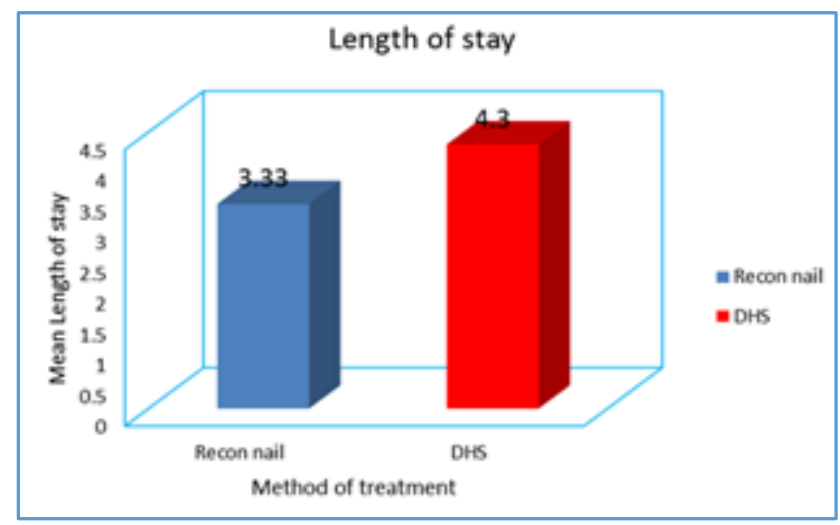

4. Union status versus Method of fixation: 29 cases out of 30 patients had fracture union at the end of 9 months in Recon nail and 27 cases out of 30 patients among DHS patients.

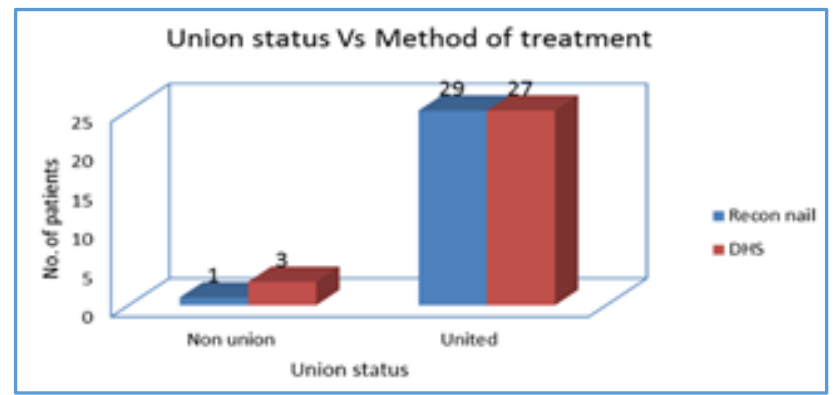

5. Harris hip score at 6-9 months versus Method of fixation: Functional outcome at 9 months between two groups were 88.4 (Recon nail) and 86.1 (DHS) with p value 0.269 suggesting that both the outcomes were comparable without significant difference.

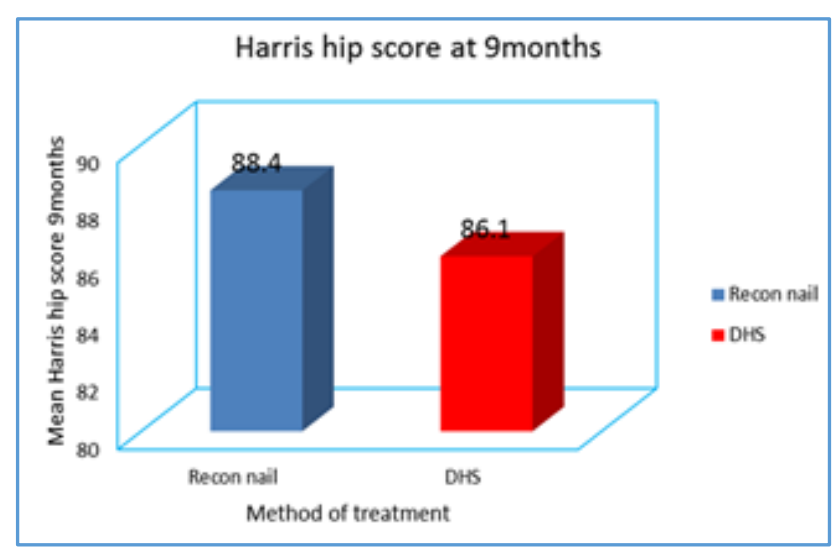

6. Final Outcome at 6-9 months versus Method of fixation: $90 \%$ of the patients had excellent to good results in Recon group and $83.3 \%$ patients had excellent to good results in DHS suggesting both are effective methods of treating intertrochanteric fractures.

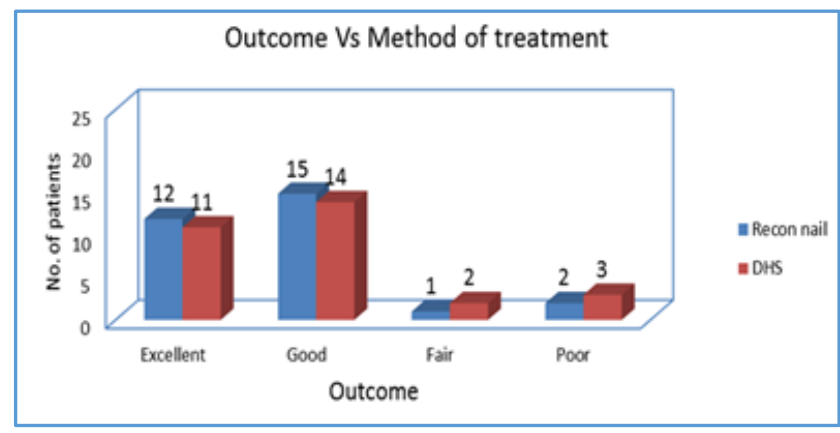

\section{DISCUSSION}

The aim of our study was to compare two different fixation devices, the extramedullary Dynamic hip screw fixation and the intramedullary fixation DePuy reconstruction nail in the treatment of intertrochanteric fractures. The primary objective of the study is to assess the functional outcome of patients treated with either of the two procedures.

All the cases were classified according to the A.O. Classification, which is the most accepted classification all over the world. All the surgeries were done either by consultants themselves or under their guidance. All the patients were followed up for an average period of 6-9 months. The functional outcome was evaluated on the basis of modified Harris Hip Score. 
Other parameters like blood loss, duration of surgery, length of hospital stay and union status of fracture were also considered to compare the outcome of two procedures.

Most of our patients in our study were elderly, the minimum age of the patient was 42 years and maximum was 84 years with a mean age of 63.05 and a standard deviation of 10.15. The average age in the I. B. Schipper et al ${ }^{1}$ study was 82.2 years, probably because they had considered patients mainly of older age group ( $>60$ years).

\begin{tabular}{|c|c|c|}
\hline Study & Recon/PFN & DHS \\
\hline Our study & 63.06 & 63.05 \\
\hline Saudan et al. ${ }^{2}$ & 83 & 83.7 \\
\hline Pan et $\mathrm{al}^{3}$ & 70 & 69 \\
\hline Papasimos et al. ${ }^{4}$ & 79.4 & 81.4 \\
\hline Pajarinen et al5 & 80.9 & 80.3 \\
\hline Shen et al6 & 72.1 & 71.2 \\
\hline Zhao et al7 & 76 & 74.5 \\
\hline \multicolumn{3}{|c|}{$\begin{array}{l}\text { Table 1. Comparison of Mean Age of Recon/ } \\
\text { PFN aroun and DHS aroun }\end{array}$} \\
\hline
\end{tabular}

Majority of the patients in our study were female comparable to I. B. Schipper study ${ }^{1}$ where majority were females (82\%). In our series, $58.33 \%$ cases were female and $41.67 \%$ cases were male. Dahl and colleagues, ${ }^{8}$ in their study noted $65 \%$ of patients were females, explained by the fact that females are more prone for the osteoporosis after menopause.

In our study, left-sided hip fractures are more common (58.33\%) compared to right hip fractures. This data is similar to the Bojan et al $^{9}$ study done on 3066 patients which has slight left-sided preponderance $(50.7 \%)$.

The most common mode of injury in our series was fall while walking or slip in bathroom, which is low velocity injury. Overall $76.67 \%$ of the cases in the current study sustained injury by this mode of injury which signifies that trochanteric fractures are caused by low energy trauma. Rest of the cases had high energy injuries like RTA, fall from height.

\section{A0 Classification}

A2 (65\%) type of fracture was the most common type of fracture compared to A1 (13.33\%) and A3 (21.67\%) in our study. This is on par with study done by Bojan et al. ${ }^{9}$ Zhao C group also had $48 \%$ of cases of A2 type fracture in their demographic data.

Duration of surgery is crucial for any surgical technique as increase in duration will increase the chances of infection. In the past, PFN has been associated with shorter operating time as compared with DHS. In a study by Nuber $S$ et al, ${ }^{10}$ they found significantly shorter operation time 44.3 (PFN group) vs. 57.3 (DHS group) min. In another study by Zhao $\mathrm{C}$ et al,7 the average time of surgery was $(51.5+/-4.4) \mathrm{min}$. in PFN; $(68.8+/-5.9)$ min. in DHS. Klinger et al ${ }^{11}$ study shows shorter procedure time (43 vs. $61 \mathrm{~min}$.) for PFN compared with DHS. In our study, we had similar results with shorter average operative time for Recon nail (75 min.) compared with DHS (128.83 min.). However, operating time may differ for different surgeons and according to complexity of fractures. Moreover, no significant difference in the operating time was found by Knobe et al ${ }^{12}$ ( 80 versus 79 minutes) for DHS versus PFN.

\begin{tabular}{|c|c|c|c|c|c|}
\hline Study & Our Study & $\begin{array}{c}\text { Nuber S } \\
\text { et al }{ }^{10}\end{array}$ & $\begin{array}{c}\text { Zhao C et } \\
\text { al }^{7}\end{array}$ & $\begin{array}{c}\begin{array}{c}\text { Klinger } \\
\text { et al } \mathbf{1}^{11}\end{array} \\
\end{array}$ & $\begin{array}{l}\text { Knobe } \\
\text { et al }{ }^{12}\end{array}$ \\
\hline $\begin{array}{c}\text { Recon } \\
\text { Nail/PFN } \\
\text { Group }\end{array}$ & 75 min. & $\begin{array}{l}44.3 \\
\text { min. }\end{array}$ & $\begin{array}{l}51.5 \\
\text { min. }\end{array}$ & $\begin{array}{c}43 \\
\text { min. }\end{array}$ & $\begin{array}{c}79 \\
\min .\end{array}$ \\
\hline $\begin{array}{c}\text { DHS } \\
\text { Group }\end{array}$ & $\begin{array}{c}128.83 \\
\text { min. }\end{array}$ & $\begin{array}{l}57.3 \\
\text { min. }\end{array}$ & $\begin{array}{l}68.8 \\
\text { min. }\end{array}$ & $\begin{array}{c}61 \\
\text { min. }\end{array}$ & $\begin{array}{c}80 \\
\text { min. }\end{array}$ \\
\hline \multicolumn{6}{|c|}{$\begin{array}{c}\text { Table 2. Comparison of Mean Operative } \\
\text { times between Recon nail/PFN groups and } \\
\text { DHS groups in various Studies }\end{array}$} \\
\hline
\end{tabular}

The DHS patients had significantly more blood loss (259.94 mL) intra-operative compared to Recon group (average $150.61 \mathrm{~mL}$ ) in our study. The comparison was statistically and clinically significant suggesting DHS has more blood loss than Recon nail patients. This is similar to the series by Baumgaertner ${ }^{9}$ and associates who also found a significant difference in the intraoperative blood loss in their series, with $150 \mathrm{~mL}$ higher for the DHS group.

Similar studies were also done comparing blood loss in Recon/PFN versus DHS and they had results which were in correlation with our findings as follows.

\begin{tabular}{|c|c|c|}
\hline Study & Recon Nail/PFN & DHS \\
\hline Our study & $150.61 \mathrm{~mL}$ & $259.94 \mathrm{~mL}$ \\
\hline Pajarinen et al ${ }^{5}$ & $320 \mathrm{~mL}$ & $357 \mathrm{~mL}$ \\
\hline Pan et al. ${ }^{3}$ & $273.33 \mathrm{~mL}$ & $480 \mathrm{~mL}$ \\
\hline Shen et al. 6 & $123.73 \mathrm{~mL}$ & $304.12 \mathrm{~mL}$ \\
\hline Zhao et al. ${ }^{7}$ & $179 \mathrm{~mL}$ & $269.3 \mathrm{~mL}$ \\
\hline \multicolumn{3}{|c|}{$\begin{array}{c}\text { Table 3. Comparison of Average Blood Loss } \\
\text { between Recon nail/ PFN groups and DHS } \\
\text { groups in various Studies }\end{array}$} \\
\hline
\end{tabular}

In our study, majority of the patients got discharged by the $4^{\text {th }}$ day postoperatively. The minimum duration was 2 days and the maximum was 7 days with a mean stay period of 3.82 days and a standard deviation of 0.93 . The average injury operational interval in our series was 2 days. The delay in surgery was primarily because majority of the patients were of geriatric age group and many of them had other medical comorbidities. In our series, $30 \%$ of the cases had associated medical comorbidities, which caused delay in surgery. However, early operative treatment gives best chance of early independence and reduces risks of prolonged immobilisation. Along with medical comorbidities, most of the geriatric age group had associated osteoarthritis of the knee joint which affects the functional results.

Most of our patients are discharged in the early postoperative period to cut down hospital expenses. In our study, average length of stay of Recon nail group is 3.3 days where as that of DHS group is 4.3 days. The results are statistically significant and also clinically significant as DHS patients undergoing an open procedure have more blood loss and increased operative time needing increased length of stay for blood transfusions, drain removal and postoperative care. Klinger et al11 study had similar outcomes showing shorter inpatient stay for PFN vs. DHS (20 vs. 24 days). Considerably, shorter inpatient stay was seen in PFN group vs. DHS (18.6 vs. 21.3 days) in Nuber $\mathrm{S}$ et $\mathbf{a l}^{\mathbf{1 0}}$ study. 


\begin{tabular}{|c|c|c|c|}
\hline Study & Our Study & $\begin{array}{c}\text { Klinger } \\
\text { et al 11 }\end{array}$ & Nuber S10 \\
\hline Recon Nail/ PFN & 3.33 days & 20 days & 18.6 days \\
\hline DHS & 4.3 days & 24 days & 21.3 days \\
\hline $\begin{array}{c}\text { Table 4. Comparison of Mean Operative Times between } \\
\text { Recon nail/PFN and DHS groups in various Studies }\end{array}$ \\
\hline
\end{tabular}

In our study, 93.33\% fractures were united at the final followup, out of which $96.67 \%$ united in Recon group and 90 $\%$ are united in DHS group. It suggests in our study Recon nail group has better outcome in terms of fracture union.

In a study by Guerra MT et al ${ }^{13}$ comparing PFN and DHS, there was no statistically significant difference between the two groups in functional recovery scores at baseline $(p=0.346)$ or at 3 months $(p=0.880)$ after surgery. However, in our study, we found that modified Harris hip score for functional outcome at 3 months was statistically significant $(\mathrm{P}$ value $=.001$ ) suggesting Recon nail patients had better functional outcome than DHS patients.

\begin{tabular}{|c|c|c|}
\hline Study & Our Study & Guerra MT et al ${ }^{13}$ \\
\hline P value at 3 months & 0.001 & 0.880 \\
\hline \multicolumn{2}{|c|}{ Table 5. Showing comparison of P values in } \\
our Study and Guerra MT et al ${ }^{13}$ Study \\
for Functional Scores at 3 Months \\
\hline
\end{tabular}

Assessment of functional scores at 9 months for the difference in outcomes between two groups was statistically insignificant in a study by Guerra MT et al ${ }^{13}$ ( $p$ 0.468) and even our study had similar results $(\mathrm{p}=0.269)$ suggesting at 9 months, both the outcomes were comparable without significant difference.

\begin{tabular}{|c|c|c|}
\hline Study & Our Study & Guerra MT et al ${ }^{13}$ \\
\hline P value at 9 months & 0.269 & 0.468 \\
\hline \multicolumn{3}{|c|}{ Table 6. Showing comparison of P values in } \\
our Study and Guerra MT et al ${ }^{13}$ Study \\
for Functional Scores at 9 Months
\end{tabular}

In a study of Kudlacik $\mathrm{K}$ et $\mathrm{al}^{14} 75 \%$ of patients who underwent gamma nail in treatment of intertrochanteric fractures had excellent and good results whereas in our study $90 \%$ of the patients in Recon nail group had excellent and good results.

\section{CONCLUSION}

In our short-term study, we arrived at following conclusions: Majority of the patients belonged to geriatric age group (more than $78 \%$ of our study were above 55 yrs.). It was observed that there was female predominance in the study group (58.33 $\%$ ) which is explained by the fact that females are more prone to osteoporosis after menopause.

Most of the patients sustained the injury because of low velocity trauma ( 46 of 60 patients in the study group sustained fractures due to low energy injuries). Procedure time for DHS (Average time-128.83 minutes) was more compared to Recon nail (Average time in the study group was 75 minutes). DHS being an open procedure, there was more blood loss than Recon nail (Mean blood loss in the study DHS vs. Recon nail $260 \mathrm{~mL}$ vs. $150 \mathrm{~mL}$ ). Patients treated with DHS needed longer duration of hospital stay than Recon nail (Mean hospital stay for DHS was 4.3 days and for Recon nail was 3.3 days). Nonunion and other complications were more in DHS group.
(There were 3 non-unions in DHS group compared to 2 nonunions in Recon nail group for same sample size in the study). Functional outcomes at 3 months were better in Recon nail (Mean modified Harris hip score for Recon nail 44.1 versus DHS 41.07) which was due to less blood loss, shorter duration of surgery, decreased hospital stay and early ambulation. The functional outcomes were statistically similar between the two groups at the end of 9 months ( $p$ value $=0.269$ ) suggesting both the outcomes were comparable without significant difference, and our study concludes that both are equally effective procedures for intertrochanteric fracture.

\section{REFERENCES}

1. Schipper IB, Steyerberg EW, Castelein RM, et al. Treatment of unstable trochanteric fractures. Randomised comparison of the gamma nail and the proximal femoral nail. J Bone Joint Surg $\mathrm{Br}$ 2004;86(1):86-94.

2. Saudan M, Lübbeke A, Sadowski C, et al. Pertrochanteric fractures: is there an advantage to an intramedullary nail?: a randomized, prospective study of 206 patients comparing the dynamic hip screw and proximal femoral nail. J Orthop Trauma 2002;16(6):386-393.

3. Pan X-h, Xiao D-m, Lin B-w. Dynamic hip screws (DHS) and proximal femoral nails (PFN) in treatment of intertrochanteric fractures of femur in elderly patients. Chin J Orthop Trauma 2004;7:785-789.

4. Papasimos S, Koutsojannis CM, Panagopoulos A, et al. A randomised comparison of $\mathrm{AMBI}$, TGN and PFN for treatment of unstable trochanteric fractures. Arch Orthop Trauma Surg 2005;125(7):462-468.

5. Pajarinen J, Lindahl J, Michelsson O, et al. Pertrochanteric femoral fractures treated with a dynamic hip screw or a proximal femoral nail. A randomised study comparing post-operative rehabilitation. J Bone Jt Surg $\mathrm{Br}$ 2005;87(1):76-81.

6. Shen H-m, Liang C-w, Fan Y-q. The clinical study of the treatment of intertrochanteric fractures in the elderly with DHS, Gamma nail and PFN. Chinese Journal of Clinical Medicine 2007;2:226-228.

7. Zhao C, Liu DY, Guo JJ, et al. Comparison of proximal femoral nail and dynamic hip screw for treating intertrochanteric fractures. Zhongguo $\mathrm{Gu}$ Shang 2009;22(7):535-537.

8. Dahl E. Mortality and life expectancy after hip fractures. Acta Orthop Scand 1980;51(1):163-170.

9. Bojan AJ, Beimel C, Speitling A, et al. 3066 consecutive Gamma Nails. 12 years experience at a single centre. BMC Musculoskelet Disord 2010;11:133.

10. Nuber S, Schnweiss T, Rter A. Stabilisierung von instabilen trochantren Mehrfragmentfrakturen Vergleich zwischen PFN und DHS mit Trochanterabsttzplatte. Unfallchirurg 2003;106(1):39-47.

11. Klinger HM, Baums $\mathrm{MH}$, Eckert $\mathrm{M}$, et al. A comparative study of unstable per- and intertrochanteric femoral fractures treated with dynamic hip screw (DHS) and trochanteric butt-press plate vs. proximal femoral nail (PFN). Zentralbl Chir 2005;130(4):301-306.

12. Knobe M, Münker R, Sellei RM, et al. Unstable pertrochanteric femur fractures. Failure rate, lag screw sliding and outcome with extra- and intramedullary 
devices (PCCP, DHS and PFN). Z Orthop Unfall 2009;147(3):306-313.

13. Guerra MTE, Pasqualin S, Souza MP, et al. Functional recovery of elderly patients with surgically-treated intertrochanteric fractures: preliminary results of a randomised trial comparing the dynamic hip screw and proximal femoral nail techniques. Injury 2014;45(Suppl 5):S26-31.

14. Kudłacik K, Jesse L, Gagaczowski T. Intramedullary osteosynthesis with gamma nail in treatment of peritrochanteric fractures of the femur. Ortop Traumatol Rehabil 2008;10(6):566-575. 